\title{
Três espécies novas de Ladoffa Young (Hemiptera, Auchenorrhyncha, Cicadellidae) ${ }^{1}$
}

\author{
Rodney Ramiro Cavichioli ${ }^{2,3}$ \\ Larissa De Bortolli Chiamolera ${ }^{2,4}$
}

\begin{abstract}
Three new species of Ladoffa Young (Hemiptera, Auchenorrhyncha, Cicadellidae). Three new species of Ladoffa Young, 1977 are described: L. rubronigra sp. n. (North Brazil and Guyana), L. isabellina sp. n. (North Brazil), and L. trifasciata sp. n. (Panama). They are similar to the other species of the genus in the general aspect, mainly with regards to the coloration. However, they can be distinguished by the aspect of the male genitalia.

KEY WORDS. Hemiptera, Auchenorrhyncha, Cicadellidae, Ladoffa, new species
\end{abstract}

Young (1977) descreveu o gênero Ladoffa, designando Tettigonia ignota Walker, 1851 como espécie-tipo. Incluiu, ainda, nesse gênero mais 23 espécies, sendo 17 novas e seis novas combinações.

O gênero é caracterizado pela coloração vermelha e preta, no aspecto dorsal, sendo que, em algumas espécies, a cabeça e ou o pronoto são marrom-avermelhado. Segundo Young (1977), Ladoffa relaciona-se com Iragua Melichar, 1926 e Diedrocephala Spinola, 1850, distinguindo-se pela estrutura da genitalia do macho, sétimo esternito das fêmeas e pela venação das asas anteriores.

LOZADA (1993) descreveu mais uma nova espécie: Ladoffa aguilari do Peru.

Analisando-se espécimens do Norte do Brasil, Guiana e Panamá foram descobertas três espécies novas: Ladoffa rubronigra sp. n., L. isabellina sp. n. e $L$. trifasciata sp. $\mathbf{n}$.

Após a retirada do abdômen dos espécimens, esse foi colocado em solução de $\mathrm{KOH}$ a $10 \%$ à frio, por 12 horas e depois, lavado em água corrente. Em seguida, foi tratado com corante "Eosina Giallastra" dissolvido em etanol, na proporção de $1 / 100$, o que permitiu uma melhor visualização das estruturas.

Os dados listados das etiquetas de procedência do material são citados com segue: (;) mudança de linha na etiqueta (/) mudança de etiqueta. O material de estudo é proveniente das seguintes instituições: Coleção de Entomologia Pe. Jesus Santiago Moure do Departamento de Zoologia da Universidade Federal do Paraná (DZUP); Instituto Nacional de Pesquisa da Amazônia (INPA); Museu de Zoologia da Universidade de São Paulo (MZSP); The Natural History Museum, Londres (BMNH).

O material tipo está depositado nas instituições designadas pela sigla citada após os dados de procedência.

1) Contribuição número 1217 do Departamento de Zoologia, Universidade Federal do Paraná.

2) Departamento de Zoologia, Universidade Federal do Paraná. Caixa Postal 19020, 81531-990 Curitiba, Paraná, Brasil.

3) Bolsista CNPq. E-mail: cavich@bio.ufpr.br

4) Bolsista PIBIC/UFPR/CNPq. 


\section{Ladoffa rubronigra sp. $\mathbf{n}$.}

Figs 1-7

Localidade-tipo. Manaus, Estado do Amazonas, Brasil.

Holótipo, macho. Manaus - "AM; Brasil 2F3 km 23; Faz[enda] Esteio Res.;1208/ 27.III.96; B. Klein leg./ 0032241”(INPA).

Parátipos. Macho, "Cica 077; Pentaclethra macroloba; Camoudi 22/VII/1997/ Hand collecting-beating; Station 6082; Seedl-Sapl-tree/ Mabura Hill; Guyana; Y. Basset, coll. / 6571" (DZUP); 1 fêmea, "Cica 077; Chlorocardium rodiei; Camoudi 13/IX/1997/ Hand collecting-beating; Station 3466; Seedl-Sapltree/ Mabura Hill; Guyana; Y. Basset, coll. / 6452" (DZUP).

Medidas em milímetros. Holótipo/parátipo fêmea: comprimento total: 6,50/6,67; comprimento mediano da cabeça: $0,72 / 0,68$; distância transocular: 1,44/1,44; distância interocular: 0,88/0,80; comprimento mediano do pronoto: 0,92/0,90; distância entre os úmeros: $1,48 / 1,42$; largura máxima do escutelo: $0,96 / 1,00$; comprimento mediano do escutelo: $0,70 / 0,82$; comprimento das tégminas: 4,83/5,12; largura máxima das tégminas: 1,44/1,32.

Holótipo macho. Cabeça, em vista dorsal, levemente pronunciada, de comprimento mediano aproximadamente $1 / 2$ da distância transocular e $6 / 5$ da distância interocular; superfície dorsal finamente pontuada; margem anterior arredondada, sem carena na transição entre a coroa e a face; ocelos mais próximos dos olhos do que entre si; superfície dorsal com uma sutura mediana entre os ocelos; lóbulos supra-antenais não protuberantes dorsalmente, em vista lateral levemente carenados; fronte, em vista lateral, fortemente convexa; clípeo contínuo à fronte, com margem apical arredondada.

Pronoto tão largo quanto a cabeça, com comprimento mediano aproximadamente $5 / 8$ da largura entre os úmeros; superfície dorsal finamente pontuada, margem posterior retilínea, arredondada nas laterais. Tégminas três vezes e meia mais longas que largas; com quatro células apicais, a base da quarta tão proximal quanto a da terceira; com três células anteapicais fechadas; margem apical emarginada; superfície lisa, com venação distinta.

Pigóforo alongado, comprimento maior que duas vezes a largura basal, com ápice angulado, sem processos, macrocerdas distribuidas no terço apical. Placa subgenital triangular, bipartida, afilada apicalmente, com uma fileira de macrocerdas lateralmente. Estilos longos, delgados, pontiagudos apicalmente, ramo basal alargado. Conetivo mais ou menos retangular com uma forte concavidade dorsal. Edeago curto, retilíneo, subcilíndrico, afilando-se para o ápice. Paráfise em forma de "V" com ápice pontiagudo, foliáceo e serrilhado.

Fêmea. Semelhante ao macho, levemente maior. Esternito VII mais ou menos retangular, com uma reentrância mediana apical. Pigóforo alongado, mais longo do que largo, com macrocerdas distribuídas por toda sua extensão.

Holótipo. Coloração, no aspecto geral, vermelha com manchas pretas. Cabeça, em vista dorsal, com o disco da coroa vermelho-acastanhado, com o ápice e margnes laterais, junto aos lóbulos supra-antenais, amarelo-pálidos. Pronoto e escutelo castanhos. Tégminas vermelhas com manchas pretas de forma irregular e ápice hialino. 
Comentários. Ladoffa rubronigra sp. n. é similar a L. variolaria Young, 1977 na forma do conetivo, porém na primeira o conetivo apresenta uma concavidade dorsal. No aspecto da paráfise é similar a L. purpurascens Young, 1977, no entanto, o ramo basal é muito curto em L. rubronigra sp. $\mathbf{n}$.

Etimologia. O nome da espécie é em relação às cores vermelhas e pretas no seu aspecto geral.
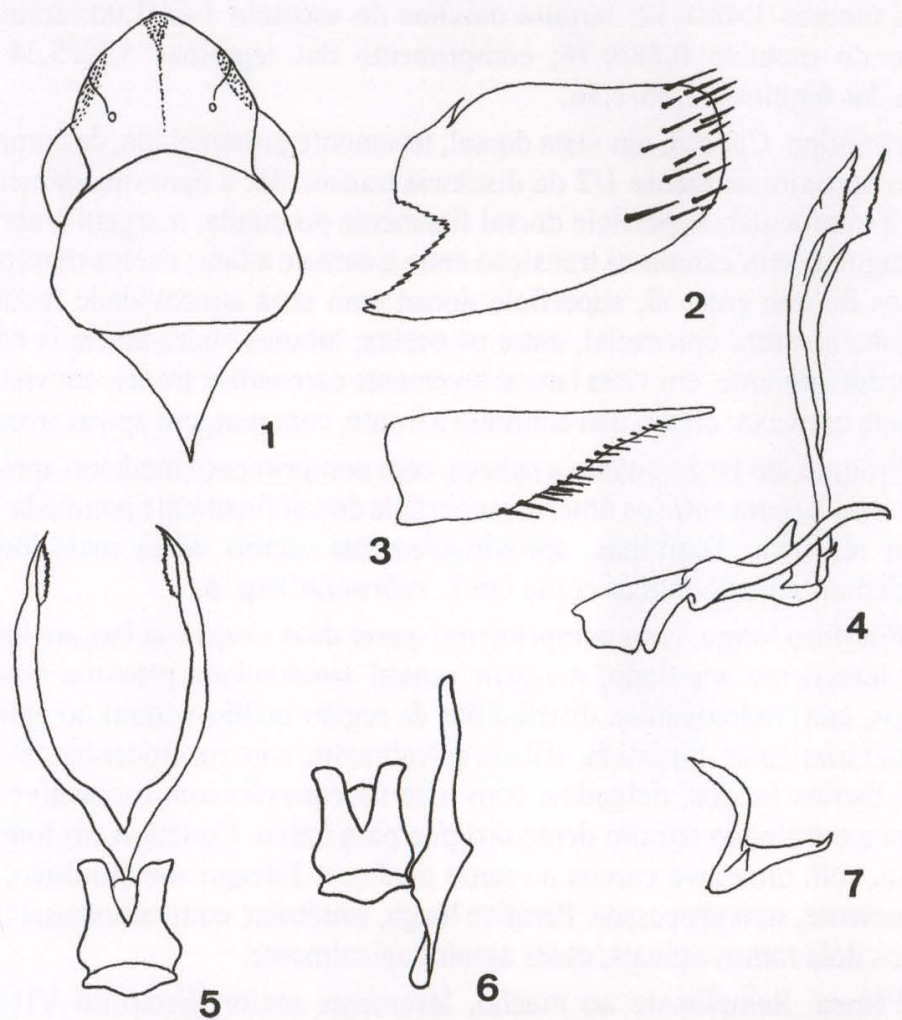

5
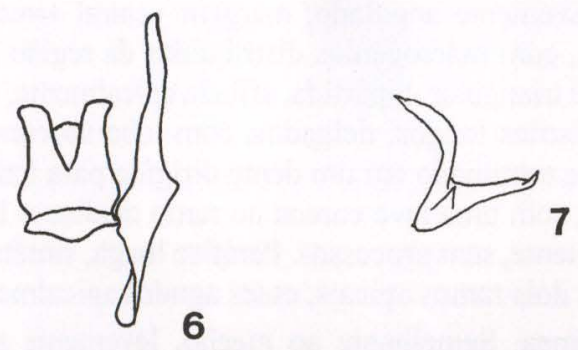

Figs 1-7. Ladoffa rubronigra sp. n., holótipo. (1) Cabeça, pronoto e escutelo, vista dorsal; (2) pigóforo, vista lateral; (3) placa subgenital, vista ventral; (4) estilo, conetivo e paráfise, vista lateral; (5) paráfise e conetivo, vista dorsal; (6) conetivo e estilo, vista dorsal; (7) edeago, vista lateral.

\section{Ladoffa isabellina sp. $\mathbf{n}$.}

Figs 8-13

Localidade-tipo. Rio Ouro Preto, Guajará-Mirim, Estado de Rondônia, Brasil.

Holótipo, macho. "Guajará-Mirim; Rio Ouro Preto; (Bananal) Brasil; 1059'23”S 6505'39”W/ 20-23.X.1995; J.A. Rafael e; A.L. Henrique leg./ $0039441 "$ (INPA). 
Parátipos. Macho e duas fêmeas. "Santa Isabel do Pará; PA, Brasil; 30/III/1962; J. Bechyné col." (DZUP); 1 fêmea, "Serra do Navio; Terr. Amapá Brasil; IX/1957; J. Lane leg." (DZUP).

Medidas em milimetros. Holótipo/fêmea: comprimento total 6,56/6,75; comprimento mediano da cabeça $0,68 / 0,72$; distância transocular $1,44 / 1,50$; distância interocular $0,88 / 0,84$; comprimento mediano do pronoto $0,92 / 0,94$; distância entre os úmeros $1,48 / 1,52$; largura máxima do escutelo 1,04/1,00; comprimento mediano do escutelo $0,88 / 0,76$; comprimento das tégminas 5,32/5,24; largura máxima das tégminas $1,36 / 1,36$.

Holótipo. Cabeça, em vista dorsal, levemente pronunciada, de comprimento mediano aproximadamente $1 / 2$ da distância transocular e aproximadamente equivalente à interocular; superficie dorsal finamente pontuada; margem anterior levemente angular; sem carena na transição entre a coroa e a face; ocelos mais próximos dos olhos do que entre si; superfície dorsal com uma concavidade mediana que acompanha a sutura epicranial, entre os ocelos; lóbulos supra-antenais não protuberantes dorsalmente, em vista lateral levemente carenados; fronte, em vista lateral, fortemente convexa; clípeo não contínuo à fronte, com margem apical arredondada.

Pronoto tão largo quanto a cabeça, com comprimento mediano aproximadamente $5 / 8$ da largura entre os úmeros; superfície dorsal finamente pontuada, margem posterior retilínea. Tégminas, aproximadamente quatro vezes mais longas que largas; demais características como em L. rubronigra sp. $\mathbf{n}$.

Pigóforo longo, com comprimento quase duas vezes sua largura basal, com o ápice levemente angulado, margem ventral arredondada próxima à base, sem processos, com macrocerdas distribuídas da região médio-ventral ao ápice. Placa subgenital triangular, bipartida, afilada apicalmente, com macrocerdas em série nas laterais. Estilos longos, delgados, com lobo na conexão com o conetivo curvado para fora e terminado em um dente dirigido para baixo. Conetivo em foma de "T" invertido, com uma leve carena no ramo mediano. Edeago subcilíndrico, curvado medianamente, sem processos. Paráfise longa, simétrica, com ramo basal tão longo quanto os dois ramos apicais, esses agudos apicalmente.

Fêmea. Semelhante ao macho, levemente maior. Esternito VII mais ou menos retangular com uma reentrância mediana apical. Pigóforo alongado, mais longo do que largo, com macrocerdas distribuídas por toda sua extensão.

Holótipo. Coloração, no aspecto geral, vermelha com manchas pretas. Cabeça, dorsalmente, avermelhada, com duas manchas castanho-claras junto as margens laterais, sobre os lóbulos supra-antenais e uma medianamente, na margem posterior. Na margem anterior, com uma faixa branca. Pronoto vermelho com uma mancha castanha em forma de "V" invertido. Escutelo com a base e ápice castanho, medianamente vermelho. Tégminas vermelhas com manchas pretas de forma irregular e ápice hialino.

Comentários. Ladoffa isabellina sp. n. é similar a L. cavillator Young, 1977 com relação à estrutura da paráfise, que apresenta o ramo basal tão longo quanto os ramos apicais e o edeago curvado dorso-apicalmente, diferindo no aspecto do conetivo, que em $L$. isabellina sp. $\mathbf{n}$. é em forma de "T" e em $L$. cavillator é 
trapezoidal, enquanto os estilos dessa última é afilado apecalmente e em $L$. isabellina $\mathbf{s p .} \mathbf{n}$. apresenta truncado apicalmente. Com relação a coloração, $L$. isabellina sp. n. apresenta truncado apicalmente. Com relação a coloração difere pela mancha em forma de "V" no pronoto.

Etimologia. O nome da espécie é alusiva a localidade de Santa Isabel do Pará, local de procedência de três espécimens, designados como parátipos.

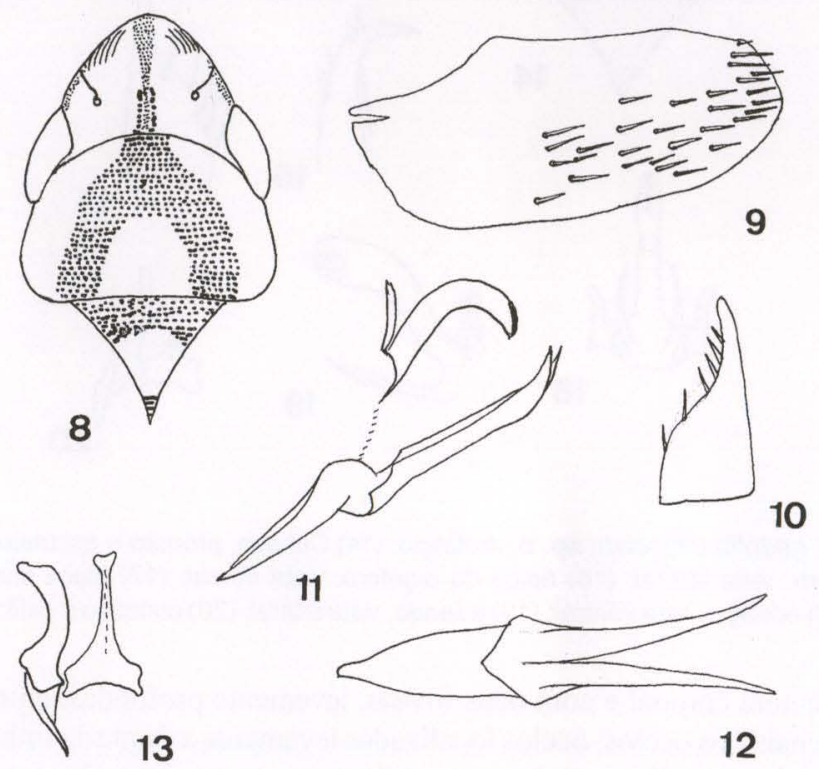

Figs 8-13. Ladoffa isabellina sp. n., holótipo. (8) cabeça, pronoto e escutelo, vista dorsal; (9) pigóforo, vista lateral; (10) placa subgenital, vista ventral; (11) paráfise e edeago, vista lateral; (12) paráfise, vista ventral; (13) estilo e conetivo, vista dorsal.

\section{Ladoffa trifasciata sp. $\mathbf{n}$.}

Figs $14-20$

Localidade-tipo. Ilha Barro Colorado, Panamá. (BMNH).

"Panama; Barro; Colorado I./I-III-1983; J.H. Martin; B.M. 1983-478"

Medidas em milímetros. Holótipo: comprimento total 6,68; comprimento mediano da cabeça 0,60 ; distância transocular 1,40; distância interocular 0,76 ; comprimento mediano do pronoto 0,92 ; distância entre os úmeros 1,48 ; largura máxima do escutelo 1,08; comprimento mediano do escutelo 0,76 ; comprimento das tégminas 5,28; largura máxima das tégminas 1,32.

Cabeça, em vista dorsal, pronunciada anteriormente, com a margem anterior subangulada; comprimento mediano 3/7 da distância transocular e 7/9 a 4/5 da distância interocular; sem carena na transição entre a coroa e a fronte; com sulco ao 

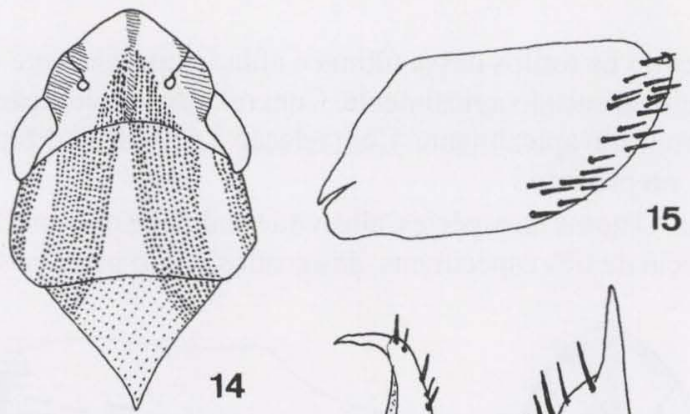

15
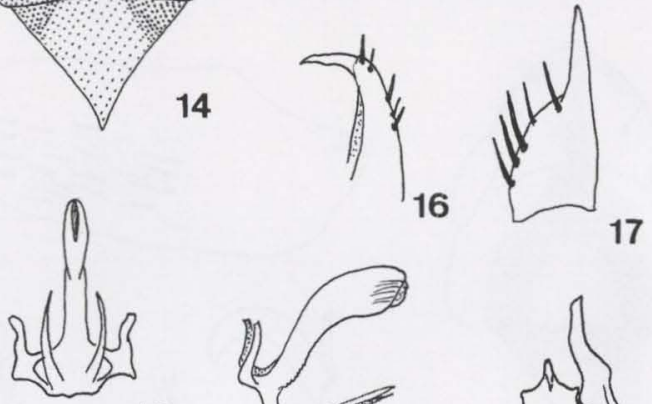

17

18
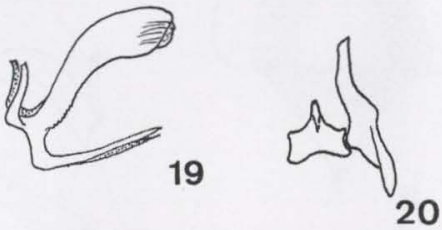

Figs 14-20. Ladoffa trifasciata sp. n., holótipo. (14) Cabeça, pronoto e escutelo, vista dorsal; (15) pigóforo, vista lateral; (16) ápice do pigóforo, vista dorsal; (17) placa subgenital, vista ventral; (18) edeago, vista ventral; (19) edeago, vista lateral; (20) conetivo e estilo, vista dorsal.

longo da sutura coronal e com duas fóveas, levemente profundas, entre os lóbulos supra-antenais e os ocelos; ocelos localizados levemente a frente da linha imaginária que tangencia os bordos anteriores dos olhos e mais próximos desses do que entre si; lóbulos supra-antenais proeminentes dorsalmente, de perfil, quase retilíneos e carenados; fronte achatada medianamente e com impressões musculares nítidas; sutura frontoclipeal completa; clípeo, de perfil, contínuo à porção apical da fronte.

Pronoto levemente mais largo do que a cabeça, com comprimento mediano 5/8 da distância entre os úmeros; margens laterais convergentes anteriormente e a posterior retilínea; esculturações ausentes. Escutelo com um sulco transverso na porção mediana e sem esculturações. Tégminas quatro vezes mais longas do que a maior largura; demais características como em L. rubronigra sp. n. e L. isabellina sp. $\mathbf{n}$.

Pigóforo duas vezes mais longo do que largo, margem posterior arredondada e afilada dorsalmente, formando um processo curto, delgado e afilado, voltado para dentro; macrocerdas junto a margem posterior. Placa subgenital, triangular, bipartida, afilada no seu terço apical e com uma fileira de macrocerdas nas margens laterais externas. Estilos longos, delgados, com lobo na articulação com o conetivo, apicalmente pontiagudos e voltados para baixo. Conetivo curto, truncado, com uma curta carena dorso-apical. Edeago longo, subcilindrico, curvo dorsalmente e ápice voltado para baixo; apicalmente mais largo que a base; com um par de processos originando-se na margem basi-ventral e dirigindo-se posteriormente, delgados e apicalmente pontiagudos e tão longos quanto o edeago. Paráfise ausente. 
Fêmea desconhecida.

Coloração, no aspecto geral, vermelha com manchas pretas de forma arredondada. Cabeça, dorsalmente vermelha, com duas faixas longitudinais castanhas entre os ocelos e convergindo anteriormente; medianamente com uma faixa longitudinal e duas faixas próximas dos ângulos anteriores dos olhos, esbranquiçadas. Pronoto castanho com três faixas vermelhas, uma mediana e duas laterais; escutelo castanho. Tégminas pretas com manchas vermelhas mais ou menos ovaladas e ápice hialino.

Comentários. Ladoffa trifasciata sp. n. é semelhante a L. scopigera Young, 1977 no aspecto do edeago, porém, o par de processos de $L$. scopigera é curvado e voltado para baixo no seu terço apical. Processo do pigóforo semelhante ao de $L$. uncata Young, 1977.

Etimologia. O nome da espécie refere-se as três faixas vermelhas no pronoto.

\section{REFERÊNCIAS BIBLIOGRÁFICAS}

LoZADA, P.W. 1991 [1993]. Una nueva especie de Ladoffa Young, 1977 (Homoptera: Cicadellidae).

Revta Per. Ent. 34: 61-62.

YouNG, D.A. 1977. Taxonomic study of the Cicadellinae (Homoptera: Cicadellidae) Part 2. New World

Cicadellini and the genus Cicadella. Bull. N. Carol. Agric. Exp. Stn. 239: 339-368.

Recebido em 06.VII.2000; aceito em 07.IV.2001. 